\title{
Measuring Particle Velocity Distribution in Circulating Fluidized Bed
}

\author{
Haneen T. Shatub ${ }^{1}$, Saad N. Saleh ${ }^{2}$, Ahmed A. Mohammed ${ }^{3}$ \\ ${ }^{1,2}$ Department of chemical Engineering, Tikrit University, Tikrit, Iraq \\ ${ }^{3}$ Department of Environmental Engineering, Baghdad University, Baghdad, Iraq
}

\begin{abstract}
A laboratory circulating fluidized bed (CFB) unit was conducted in a $6 \mathrm{~cm}$ i.d., $150 \mathrm{~cm}$ high riser made up of Plexiglas, operated under ambient conditions and various sizes of particles and different superficial gas velocities. The air-solid flow behavior of the CFB riser was video recorded and the videos were analyzed to determine the average particles distribution. Increasing the superficial air velocity caused increasing in the average particle velocities but increasing the particles size caused decreasing the average particles velocity.
\end{abstract}

Keywords: CFB, riser, flow regime, particle velocity, two phase

\section{Introduction}

Circulating fluidized bed is fluidized bed unit when worked over the terminal velocity of the particles. The particles can be separated from the air by a cyclone and recycled to the bed. A part of the unit where the carryover of the solid transpires is normally referred to as the riser $[1,2]$. Figure 1 shows a schematic of typical circulating fluidized bed system

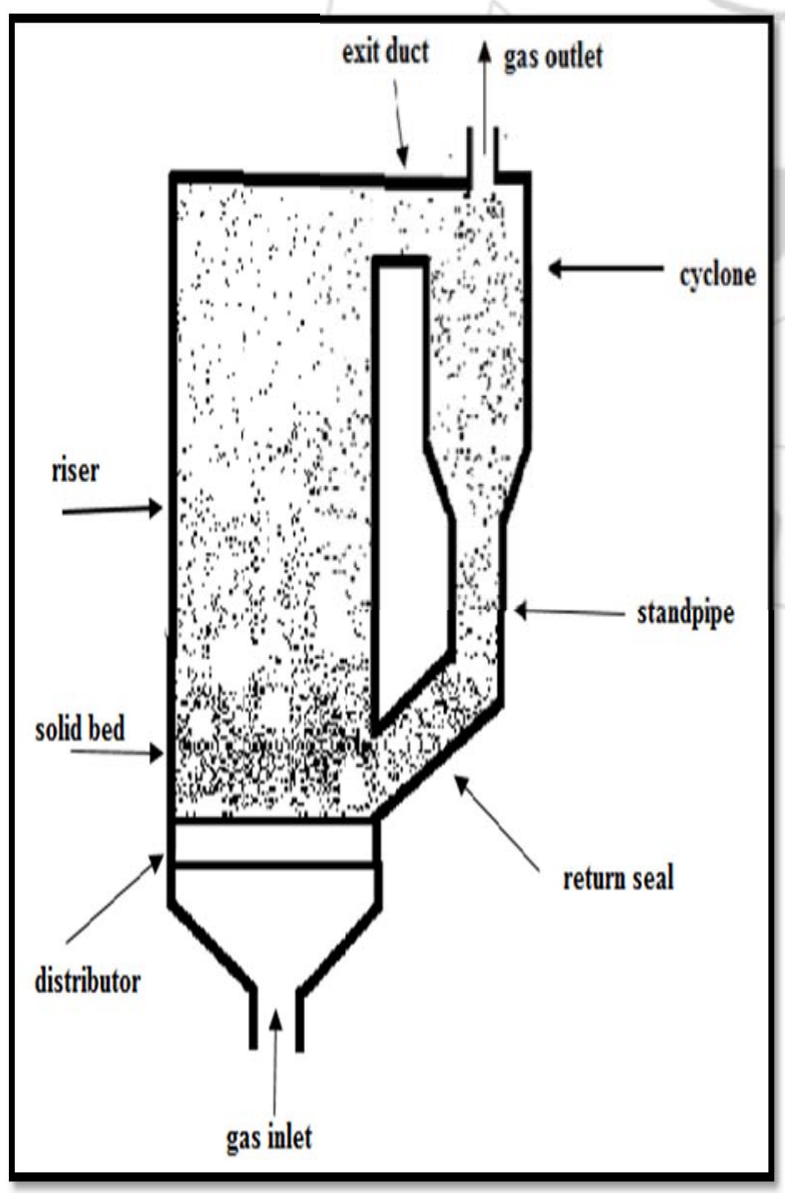

Figure 1: Schematic of typical circulating fluidized bed system [3]
Circulating fluidized bed (CFB) is successfully and widely used in commercial operations such as fluidized catalytic cracking and drying. Many important factors influence flow behavior in a circulating fluidized bed such as the inlet and exit configuration, particle size and distribution and velocity distribution of the gas as well as the solids. The hydrodynamics of gas and solids will also affect heat transfer, reaction kinetics, and catalyst activity.

The particles are directed upwards in the core of the column with a magnitude of velocity similar to the superficial gas velocity at the riser axis as seen in Figure 2. The average particle velocity then fall as the radial position moves toward the wall, becoming negative in layer adjacent to the wall. Ascending particles are dominant in the center of the riser, whereas there are more descending than ascending particles near the wall. The magnitudes of the velocities of rising particles at the axis of the riser are similar to the superficial gas velocity, while the magnitudes of downward velocities are significantly lower [4]

There are many techniques of measuring the particles velocity. Photographic and video techniques can provide information on particle velocity, direction of motion, and acceleration. However, small, fast-moving particles are difficult to photograph. Backlighting can be used for contrast in two-dimensional risers [5] as well as circular or square columns [6], A high speed camera is used to record images of the particles in the illuminated plane. Two subsequent images of the flow, separated by a short time delay, $\Delta \mathrm{t}$, are divided into small interrogation areas. Particle image velocimetry is a non-intrusive technique for the measurement of an instantaneous velocity field in one plane of a flow. The flow is visualized by seeding it with small tracer particles that perfectly follow the flow. In gas-particle flows, the discrete particles can readily be distinguished, so no additional tracer particles are needed to visualize the particle movement. 


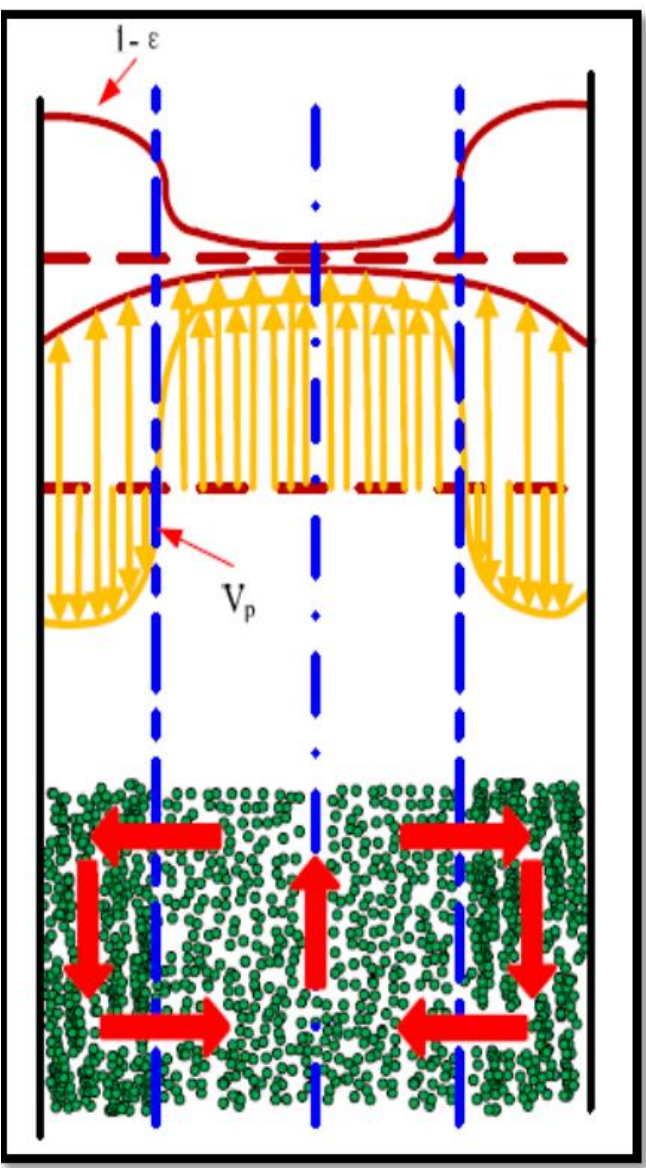

Figure 2: Schematic profile of radial solids flow structure [7].

Laser Doppler anemometry, a laser beam is split into two beams of equal intensity, which are then focused at the measuring point, forming a fringe pattern in the intersection region. When a particle passes normal to the fringes, the intensity of its reflected light varies with a frequency proportional to the particle velocity and inversely proportional to the fringe spacing. Particle velocities can also be detected by tracking the trajectory of a single tagged particle over extended time [8]. However, it is currently very difficult to track particles smaller than about $0.5 \mathrm{~mm}$ in diameter, so that the technique has not yet contributed significantly to CFB research. A some of pervious work for measuring particle velocity in CFB can be summarized as shown in table 1

Table 1: A summary of previous works

\begin{tabular}{|c|c|c|}
\hline References & $\begin{array}{c}\text { Method used } \\
\text { numerical }\end{array}$ & $\begin{array}{c}\text { Laser doppleranumometry , 3D } \\
\text { CFB system, } D_{\text {riser }} \\
=0.0508 \mathrm{~m}_{\text {riser }}=2.75 \mathrm{~m}\end{array}$ \\
\hline$[10]$ & $\begin{array}{c}\text { Experimental and } \\
\text { numerical }\end{array}$ & $\begin{array}{c}\text { video techniques, 2D CFB } \\
\text { system, Hriser }=3 \mathrm{~m}, \\
\text { Wriser }=0.4 \mathrm{~m}\end{array}$ \\
\hline$[11]$ & $\begin{array}{c}\text { Experimental and } \\
\text { numerical }\end{array}$ & $\begin{array}{c}\text { video techniques and LDA ,3D } \\
\text { CFB system }\end{array}$ \\
\hline
\end{tabular}

\section{Experimental Work}

A cold flow CFB test rig was designed, constructed and operated under standard condition $\left(\mathrm{T}=25^{\circ} \mathrm{C}, \mathrm{p}=1\right.$ atm $)$ as shown in Figure 3 and Figure 4. It consists of a riser $(6 \mathrm{~cm}$ I.D and $150 \mathrm{~cm}$ hight) where particles are transported up by co-flowing gas, a standpipe to return the particles to the bottom, and a cyclone to separate the particles from the air.

First step for measuring the average particles velocity was coloring the sand in different acrylic color (green, black, orange), each color referred to specific particle size (710 $\mu \mathrm{m}, 250 \mu \mathrm{m}$, heterogeneous).The colored sand replaced in the riser at bed height $4 \mathrm{~cm}$ thenmovie of operation the $\mathrm{CFB}$ was recorded at different flow rate using high speed camera (SONY- CYBER/SHOT DSC- H70), the images of this movie were processed using "Photron FASTCAM Viewer" the particles velocities were measured in pixels. The pixel measurements were converted to millimeters through known measurement: 1 pixel $=0.0244 \mathrm{~mm}(\mathrm{KIAN}$ and JUNIOR).

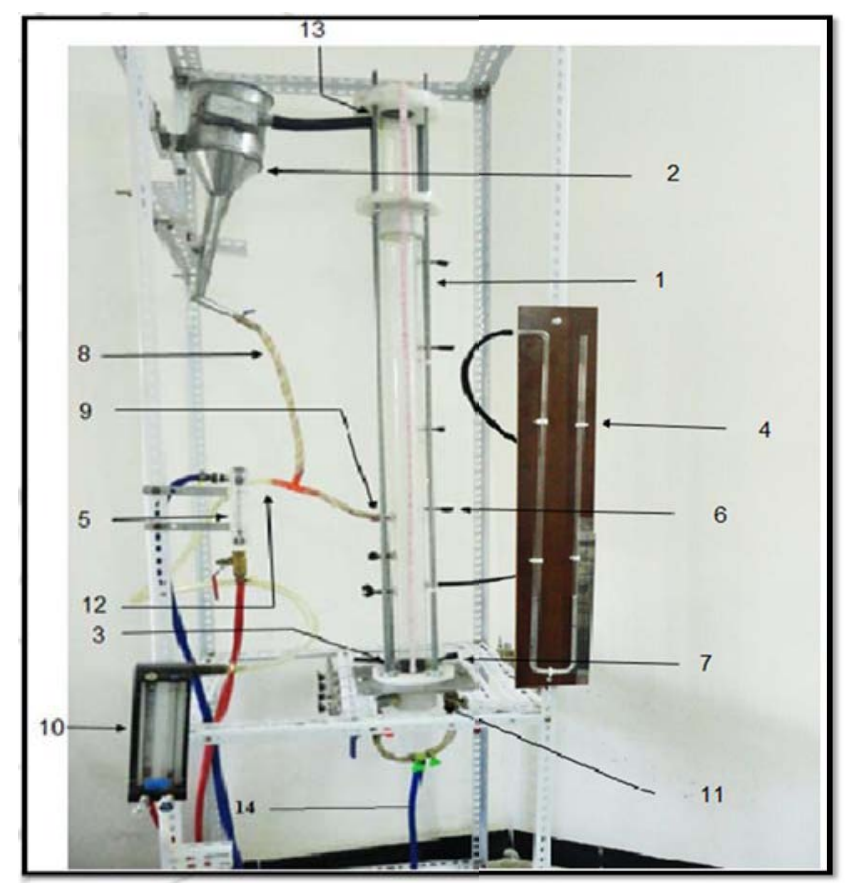

Figure 3: photographic diagram for the experimental apparatus, $1 \rightarrow$ riser, $2 \rightarrow$ cyclone, $3 \rightarrow$ distributor, $4 \rightarrow$ parameter, $5 \rightarrow$ flow meter, $6 \rightarrow$ pressure probe, $7 \rightarrow$ particle drain, $8 \rightarrow$ down comer, $9 \rightarrow$ L-valve recycle inlet, $10 \rightarrow$ secondary flow meter, $11 \rightarrow$ riser inlet plenum, $12 \rightarrow$ secondary air inlet, $13 \rightarrow$ riser exit connector (right angle), $14 \rightarrow$ main air inlet. 


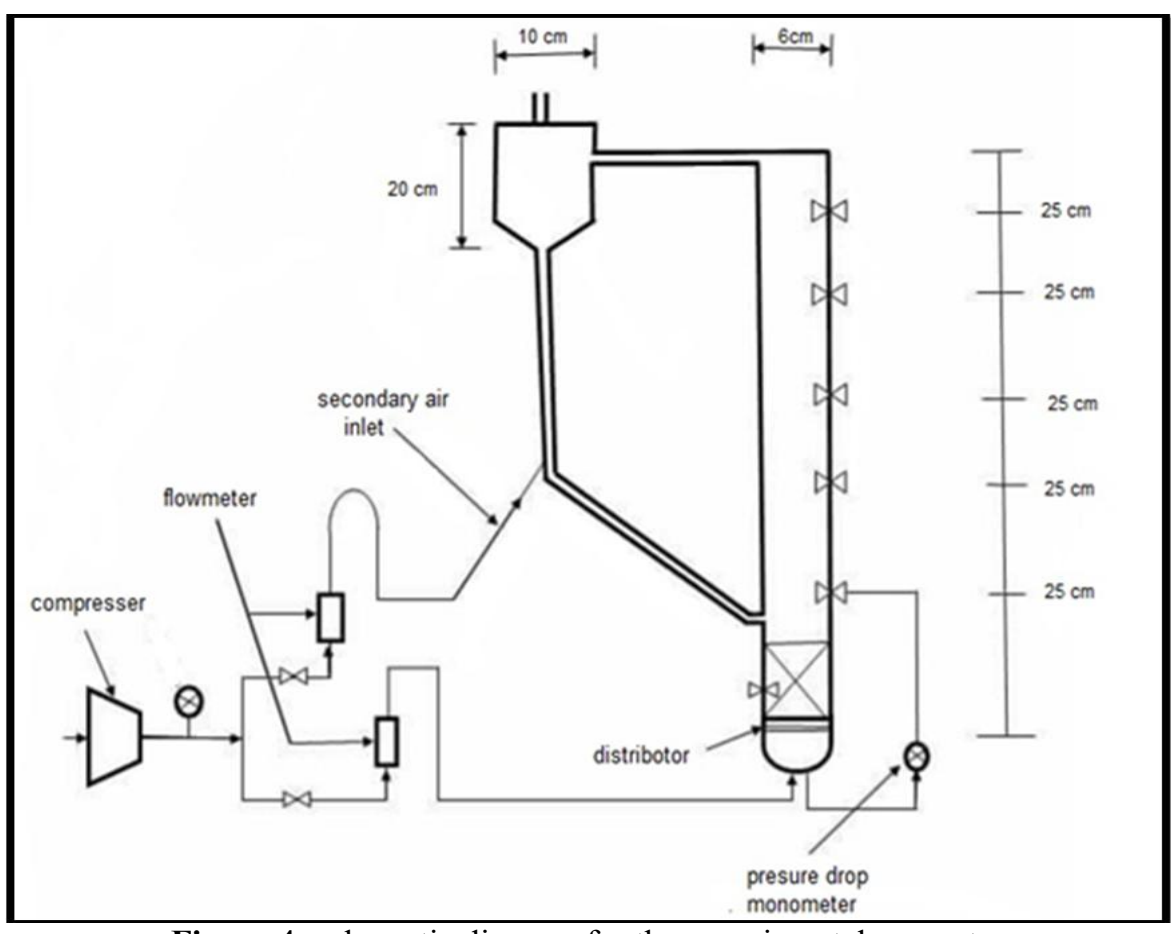

Figure 4: schematic diagram for the experimental apparatus

\section{Result and Discussion}

Firstly, specifying an appropriate flow regime of operation CFB (turbulent regime) by selecting the superficial air velocity according to dimensions of the riser, size of particles, and height of the bed. The following correlation equations were adopted to predict $\left(U_{m f}, U_{m b}, U_{m s}, U_{t}, U_{c}, U_{t r}\right)$ in order to know the operation fluidization regime depended on base case as tabled in table 2

Table 2: Main parameters of the base case

\begin{tabular}{|c|c|}
\hline Parameter & Value \\
\hline$H_{\text {bed }}$ & $20 \mathrm{~cm}$ \\
\hline$d_{p}$ & $250 \mu \mathrm{m}$ \\
\hline$U_{g}$ & $U_{g 1}=0.78 \mathrm{~m} / \mathrm{s}$ \\
& $U_{g 2}=1.18 \mathrm{~m} / \mathrm{s}$ \\
\hline$G_{s}$ & $24.4 \quad \mathrm{gm} / \mathrm{s}$ \\
\hline
\end{tabular}

Minimum Fluidization Velocity, $U_{m f}$ :

$$
\begin{gathered}
R e_{m f}=\sqrt{27.2^{2}+0.0408 A r}-27.2 \\
U_{m f}=\frac{R e_{m f} \cdot \mu_{g}}{\rho_{g} d_{p}},
\end{gathered}
$$

Where $\quad A r=\frac{g \rho_{g}\left(\rho_{p}-\rho_{g}\right) d_{p}^{8}}{\mu_{g}{ }^{2}}$

$U_{m f}=0.062 \mathrm{~m} / \mathrm{s}$

$\left(U_{g 1} \& U_{g 2}>U_{m f}\right)$

Beyond the $U_{m f}$ all solid particles are suspended by the gas and the studying system is not fixed bed.

Minimum bubbling Velocity, $U_{m b}$ : for Geldart B, the $U_{m b}=$ $U_{m f}=0.062 \mathrm{~m} / \mathrm{s} \quad\left(U_{g 1} \& U_{g 2}>U_{m b}\right)$. So beyond the $U_{m b}$, the riser exceeds the free bubbling fluidization regime.

Minimum Slugging Velocity, $U_{m s}$ :

$$
U_{m s}=U_{m f}+0.07 \sqrt{g D}
$$

$U_{m s}=0.116 \mathrm{~m} / \mathrm{s}$

$\left(U_{g 1} \& U_{g 2}>U_{m s}\right)$

Particle Terminal Velocity,

$U_{t}=0.407 \mathrm{~m} / \mathrm{s} \quad\left(U_{g 1} \& U_{g 2}>U_{t}\right)$

Onset of Turbulent Fluidization Regime:

$$
R e_{c}=0.57 A r^{0.46}
$$

$U_{c}=0.96 \mathrm{~m} / \mathrm{s}$

$\left(U_{g 2}>U_{c}>U_{g 1}\right)$

Onset of Fast Fluidization Regime:

$U_{t r}=2.7 \mathrm{~m} / \mathrm{s}$

$$
R e_{t r}=0.169 A r^{0.545}\left(D_{t} / d_{p}\right)^{0.3}
$$

$\left(U_{g 1} \& U_{g 2}<U_{t r}\right)$

Based on the preceding steps, the operating flow regime of the CFB riser for the base case was as following:-

A. At $\operatorname{Ug} 1(0.78 \mathrm{~m} / \mathrm{s})$, the operating flow regime of the CFB riser was slug fluidization regime.

B. At $U_{g_{2}}(1.18 \mathrm{~m} / \mathrm{s})$, the operating flow regime of the CFB riser was turbulent fluidization regime.

It is important to mention that the CFB riser operated at $\left(U_{g 2}\right)$ was observed experimentally with undistinguishable upper bed surface which is considered as main feature of the turbulent fluidization regime.

Effect of air superficial velocity on the particle velocity at different particle size can be seen in Fig (5-7)

The most interesting observation in the measured of the average particles velocities was that the increasing in particles diameter cause decreasing the average particle velocity as shown in compering Figure $5\left(\mathrm{~d}_{\mathrm{p}}=250 \mu \mathrm{m}\right)$ with Figure $7\left(\mathrm{~d}_{\mathrm{p}}=710 \mu \mathrm{m}\right)$. This phenomenoummay be explained

\section{Volume 6 Issue 1, January 2017}




\section{International Journal of Science and Research (IJSR) \\ ISSN (Online): 2319-7064 \\ Index Copernicus Value (2015): 78.96 | Impact Factor (2015): 6.391}

by the fact that smaller particles will follow the gas more effectively than the large ones. The large particles will not follow the gas effectively and start accumulating particularly at the wall region where the gas velocity is lower. It can be noted that the increasing in superficial air velocity cause increasing particle average velocity because of increasing the particles momentum.

These result shows good agreement awith what reported in literature [12-14] which confirm that the CFB unit must be operated above the terminal velocity of the particles.

The video recorded used depends on the accuracy of the high speed camera and didn't show the positive and negative velocity but it indicate only the average particle velocities $[10,15]$.

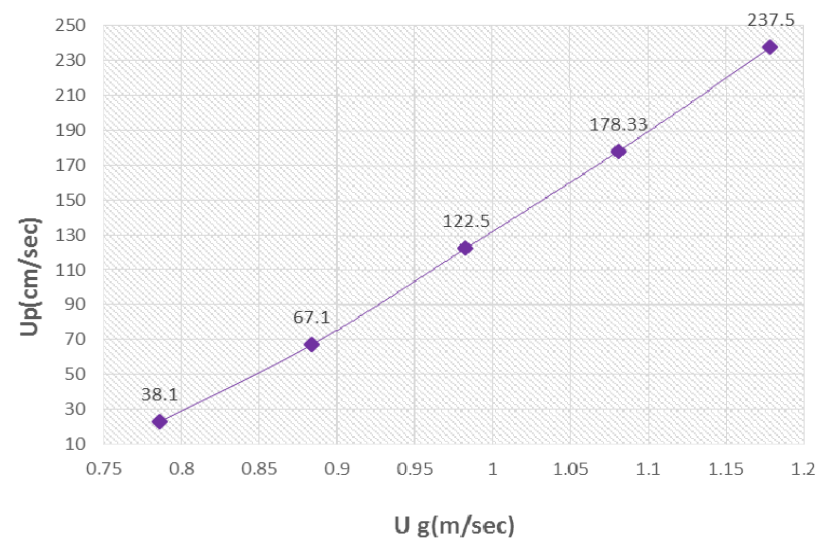

Figure 5: Relationship between average particles velocity and superficial gas velocity, $\mathrm{d}_{\mathrm{p}}=250 \mu \mathrm{m}$.

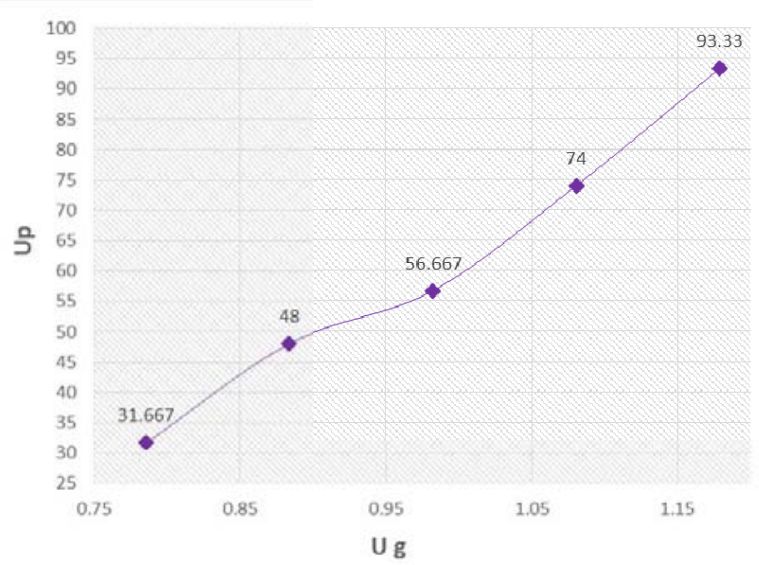

Figure 6: Relationship between average particles velocity and superficial gas velocity, $d_{p}=710 \mu \mathrm{m}$

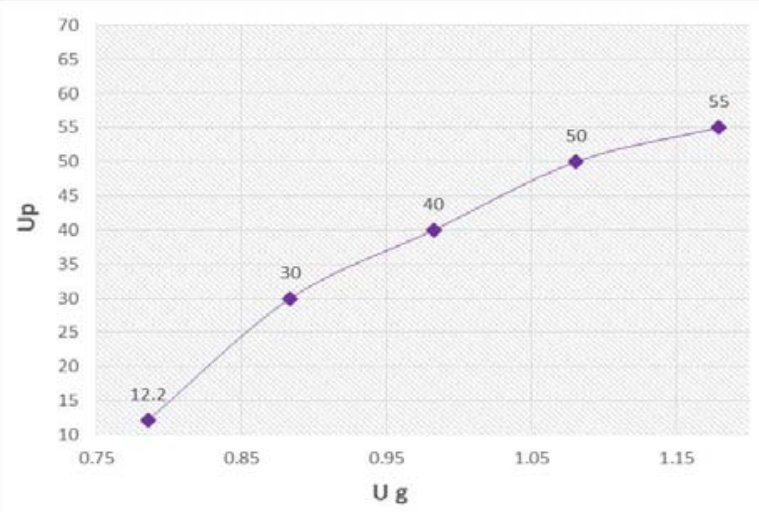

Figure 7: Relationship between average particles velocity and superficial gas velocity, heterogeneous particles size.

\section{Conclusions}

The operation regime of the CFBs systems had a major effect on the average particles distribution because of the increasing in superficial air velocitycause increasing particle average velocity because of increasing the particles momentum and The particle size also effect the average particles distribution (increasing the particle size cause decreasing the average particle velocities). The video recorded is indicate only the average particle velocity without showing positive (at the center) and negative (at the wall) values.

\section{Nomenclature}

$\mathrm{Ug}=$ superficial velocity, $\mathrm{m} / \mathrm{s}$

$\mathrm{Umf}=$ minimum fluidization velocity, $\mathrm{m} / \mathrm{s}$

$\mathrm{Umb}=$ minimum bubbling velocity, $\mathrm{m} / \mathrm{s}$

$\mathrm{Ums}=$ minimum slugging velocity, $\mathrm{m} / \mathrm{s}$

$\mathrm{Ut}=$ terminal velocity, $\mathrm{m} / \mathrm{s}$

$\mathrm{Utr}=$ transition velocity, $\mathrm{m} / \mathrm{s}$

$\mathrm{Ar}=$ Archimedes number

$\mathrm{Re}=$ reynold number

$\rho \mathrm{g}=$ gas density, $\mathrm{kg} / \mathrm{m}^{3}$

$\rho \mathrm{p}=$ particles density, $\mathrm{kg} / \mathrm{m}^{3}$

$\mathrm{dp}=$ particles diameter, $\mu \mathrm{m}$

$\mathrm{g}=$ gravity $\mathrm{m}^{2} / \mathrm{sec}$

$\mu=$ viscosity, $\mathrm{kg} / \mathrm{m} . \mathrm{s}$

\section{References}

[1] Benyahia, S., et al., Simulation of particles and gas flow behavior in the riser section of a circulating fluidized bed using the kinetic theory approach for the particulate phase. Powder Technology, 2000. 112(1): p. 24-33.

[2] Al-Dahhan, M., et al., Flow Mapping in a Gas-Solid Riser via Computer Automated Radioactive Particle Tracking (CARPT), 2005, Washington University.

[3] Andreux, R., et al., Hydrodynamic and solid residence time distribution in a circulating fluidized bed: Experimental and 3D computational study. Chemical Engineering and Processing: Process Intensification, 2008. 47(3): p. 463-473.

[4] Pärssinen, J. and J.-X. Zhu, Particle velocity and flow development in a long and high-flux circulating 


\section{International Journal of Science and Research (IJSR) \\ ISSN (Online): 2319-7064}

Index Copernicus Value (2015): 78.96 | Impact Factor (2015): 6.391

fluidized bed riser. Chemical Engineering Science, 2001. 56(18): p. 5295-5303.

[5] Arena, U., et al., Solids flow structures in a twodimensional riser of a circulating fluidized bed. Journal of chemical engineering of Japan, 1989. 22(3): p. 236241.

[6] Rhodes, M., H. Mineo, and T. Hirama, Particle motion at the wall of the $305 \mathrm{~mm}$ diameter riser of a cold model circulating fluidized bed, in Circulating Fluidized Bed Technology III1991, Pergamon Press Oxford. p. 171176.

[7] Bi, H. and L.S. Fan, Existence of turbulent regime in gas-solid fluidization. AIChE journal, 1992. 38(2): p. 297-301.

[8] Godfroy, L., et al., Simultaneous measurement of the 3$D$ position and velocity of a single radioactive particle in a CFB riser at high velocity. Proceedings of CFB V, Beijing, China, 1996.

[9] Mathiesen, V., et al., Experimental and computational study of multiphase gas/particle flow in a CFB riser. AIChE journal, 1999. 45(12): p. 2503-2518.

[10] Kallio, S., et al., Experimental and numerical study of hydrodynamics in a circulating fluidized bed. Proceedings of Finnish-Swedish Flame Days, Naantali, 2009.

[11]He, Y., et al., Gas-solid two-phase turbulent flow in a circulating fluidized bed riser: an experimental and numerical study. 2006.

[12] Almuttahar, A.M., CFD modeling of the hydrodynamics of circulating fluidized bed riser, 2006, University of British Columbia.

[13]Hussain, A., et al., EXPERIMENTAL AND COMPUTATIONAL STUDIES OF THE HYDRODYNAMICS OF THE RISER OF A CIRCULATING FLUIDIZED BED.

[14] Arjmandi-Tash, O., A. Zarghami, and R. Zarghami, Dominant Flow Structures in Gas-Solid Fluidized Beds Using Time and Frequency Domains Analyses. Particulate Science and Technology, 2014. 32(5): p. 498-505.

[15] Komvokis, V., et al., Zeolites in Fluid Catalytic Cracking (FCC), in Zeolites in Sustainable Chemistry2016, Springer. p. 271-297. 